\title{
Resource investigation for Kichiji rockfish by autonomous underwater vehicle in Kitami-Yamato bank off Northern Japan
}

\author{
Yuya Nishida ${ }^{{ }^{*}}$, Tamaki Ura ${ }^{2^{*}}$, Tomonori Hamatsu ${ }^{3^{*}}$, Kenji Nagahashi ${ }^{{ }^{*}}$, Shogo Inaba ${ }^{4^{*}}$ and Takeshi Nakatani ${ }^{5^{*}}$
}

\begin{abstract}
Expensive kichiji rockfish is important catch for fishers and decreas significantly by over fishing. Common investigation method by the trawl for the fish is difficult to survey on rough terrain and need for big support of the ship. This paper proposes resource investigation method for kichiji rockfish using autonomous underwater vehicle (AUV) Tuna-Sand, and image processing method for precise measurement of the fish length. The AUV Tuna-Sand was developed for survey of material and energy resources in deep-sea such, and can observe natural seafloor automatically using only mounted sensors and devices. Our image processing makes a photograph possible to measure accurately the fish length by color correction for removing the unevenness of the brightness and distortion correction.

The AUV Tuna-Sand surveyed for 24 hours in Kitami-Yamato Bank off Northern Japan. The vehicle took about 5,300 pictures of the seafloor during five dives in the bank. 37 kichiji rockfish of about 90 to $340 \mathrm{~mm}$ long were in all photographs. The survey results showed the fish of 150 to $200 \mathrm{~mm}$ long was most often found in all dives although the number of the othSer long was not many. Six mosaic images made by our method showed that all kichiji rockfish stay on the seafloor by oneself without swam and the shortest distance between kichiji rockfish was $4.0 \mathrm{~m}$.
\end{abstract}

Keywords: AUV; Resource investigation; Photomosaic

\section{Background}

Expensive kichiji rockfish (Sebastolobus macrochir) live in the Pacific side of main island, Pacific ide Hokkaido in Japan and southwest Okhotsk Sea. The catch of the fish has decreased significantly by over fishing. Widely regular survey of the biomass for kichiji rockfish is necessary to keep its sustainable use [1]. The biomass of benthic kichiji rockfish is investigated commonly by combination of the trawl survey and swept-area method [2]. The method which can survey effectively in a wide

\footnotetext{
*Correspondence: ynishida@iis.u-tokyo.ac.jp; ura@iis.u-tokyo.ac.jp; newmory@ fra.affrc.go.jp; nagahak@iis.u-tokyo.ac.jp; shogo@iis.u-tokyo.ac.jp; tnakatani@ jamstec.go.jp

${ }^{1}$ Institute of Industrial Science, the University of Tokyo, 4-6-1 Komaba, Tokyo, Japan

${ }^{2}$ Kyushu Institute of Technology, 2-4 Hibikino, Wakamatsu, Kitakyushu,

Fukuoka, Japan

${ }^{3}$ Hokkaido National Fisheries Research Institute, 115 Katsurakoi, Kushiro,

Hokkaido, Japan

${ }^{4}$ The University of Tokyo, 4-6-1 Komaba, Tokyo, Japan

5Japan Agency for Marine-earth Science and Technology, 2-15 Natsushima, Yokosuka, Kanagawa, Japan
}

are, is difficult to apply on rough terrain, and has a risk for damaging to the natural habitat. Researchers proposed other resource investigations method for kichiji rockfish such as method using deep-sea monitoring system $[3,4]$ and method using manned submersible vessel $[5,6]$, because the fish usually stay on seafloor without moving and have a high visibility in the photograph. Two methods can survey the biomass of the fish without sampling. However, the monitoring system requires the support from many ship staff for towing type and the submersible vessel limits duration time for the survey to ensure the safety of the vessel operator.

The AUV Tuna-Sand $[7,8]$ was developed for the survey of material and energy resources in deep-sea such as hydrothermal vent and methane hydrate. The vehicle can observe natural seafloor automatically using only mounted sensors and devices, and can be operated on every ship which has the crane for launching and lifting. We surveyed hydrothermal chimney and the seafloor using the AUV Tuna-Sand in many Japanese marine areas, and the 
Table 1 Specification of the AUV Tuna-Sand

\begin{tabular}{ll}
\hline Dimension & $1.1 \mathrm{~m} \times 0.7 \mathrm{~m} \times 0.7 \mathrm{~m}$ \\
Weight & $278 \mathrm{~kg}$ \\
Maximum velocity & $1.7 \mathrm{knot}$ \\
Maximum depth & $1500 \mathrm{~m}$ \\
Duration & $8.0 \mathrm{~h}$ \\
Actuators & Thrusters $220 \mathrm{~W} \times 4,100 \mathrm{~W} \times 2$ \\
Battery & Li-ion battery 50.4 V, 18 Ah $\times 4$ \\
Sensors & INS, GPS, DVL, Depth sensor, SSBL \\
Observation devices & Video camera, Digital camera, Profiling sonar
\end{tabular}

vehicle dived 69th times for the survey since 2007. This paper proposes resource investigation method of benthic life using the AUV Tuna-Sand, reports the result of the survey for kichiji rockfish in Okhotsk Sea on June 2013.

\section{Methods}

\section{Outline of AUV "Tuna-Sand"}

Hovering type AUV "Tuna-Sand" shown its specification in Table 1 can dive until 1,500 $\mathrm{m}$ depth. The vehicle consist of two floaters mad of syntactic foam, central hull for control circuits and electrical devices and bottom two hulls for lithium-ion batteries. Two $100 \mathrm{~W}$ thrusters for vertical motion and four $220 \mathrm{~W}$ thrusters for horizontal motion control five degrees-of-freedom of motion. Pitch and roll direction of the vehicle are static stability because of a long distance between center of gravity and buoyancy. The vehicle position is estimated with accuracy by mounted sensors such as inertial navigation system (INS) consisting of three-axis fiber optical gyro and acceleration sensor, doppler velocity log (DVL) for measuring ground speed and depth sensor. Lightsection method using a sheet laser and a forward camera measures the distance to forward obstacle for obstacle avoidance, and is also used for measuring threedimensional shape of the chimney [9]. A still camera locking downward take pictures of the seafloor using a single strobe as shown in Figure 1. The method can observe natural benthic life on the seafloor, because the flash light of the strobe is less irritating to animals than the other lights. Imaging survey by the AUV Tuna-Sand with a still camera and a strobe is effective for resource investigation and biological research of benthic life. The vehicle has profiling sonar for terrain measurement as other observation device.

\section{Survey procedure}

The AUV Tuna-Sand can be deployed in the ocean without special shipboard equipment, the ship stuffs have so little work to do during observation. Figure 2 shows survey procedure of the AUV Tuna-Sand. After alignment of an INS using GPS data, the vehicle with

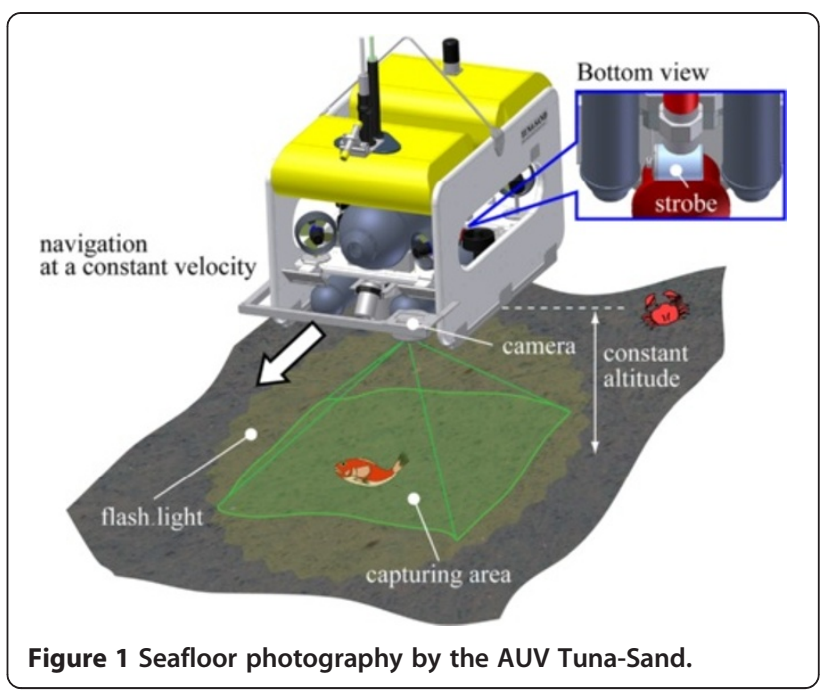

two weights for diving and surfacing is lunched in the sea. And the vehicle dives by only one's own weight without thruster force for saving power resource. The vehicle gets neutral buoyancy by releasing a mounted weight after reaching to the height which a DVL can

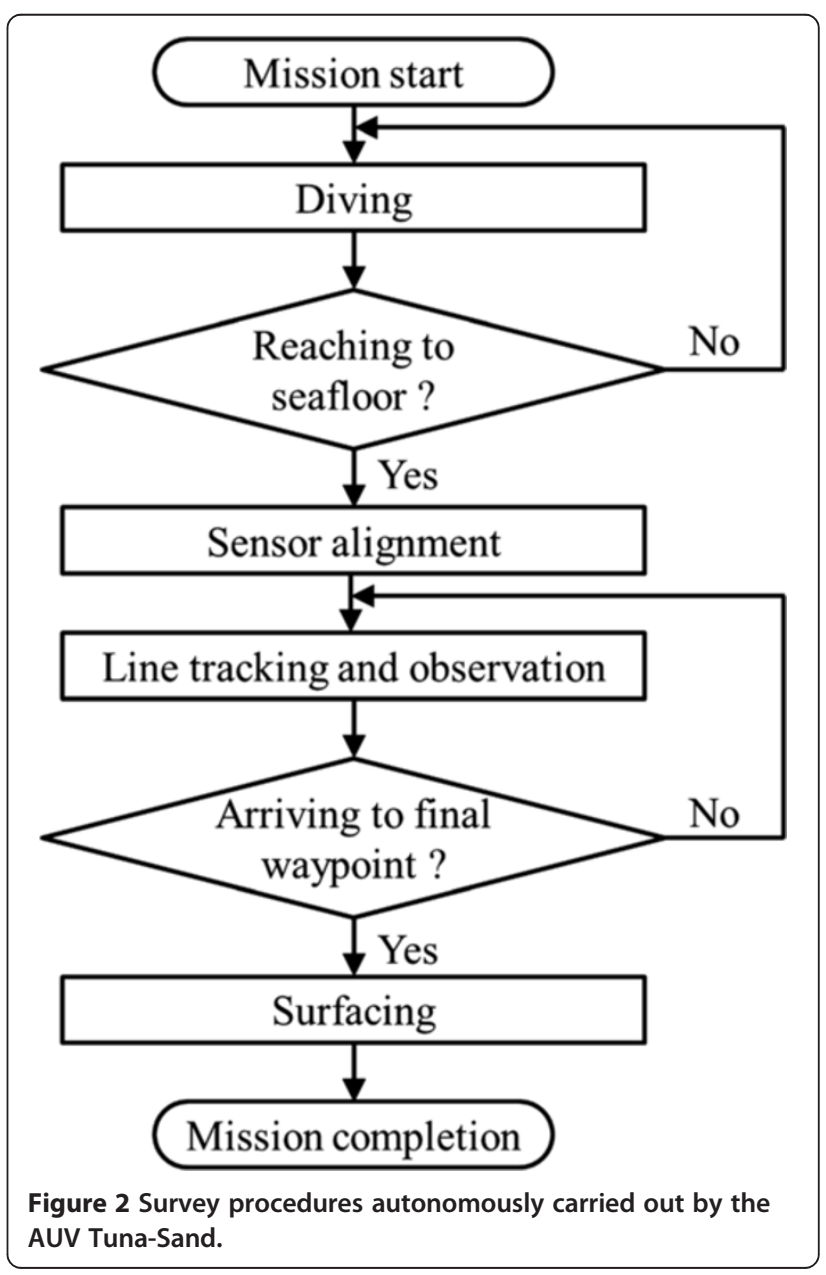




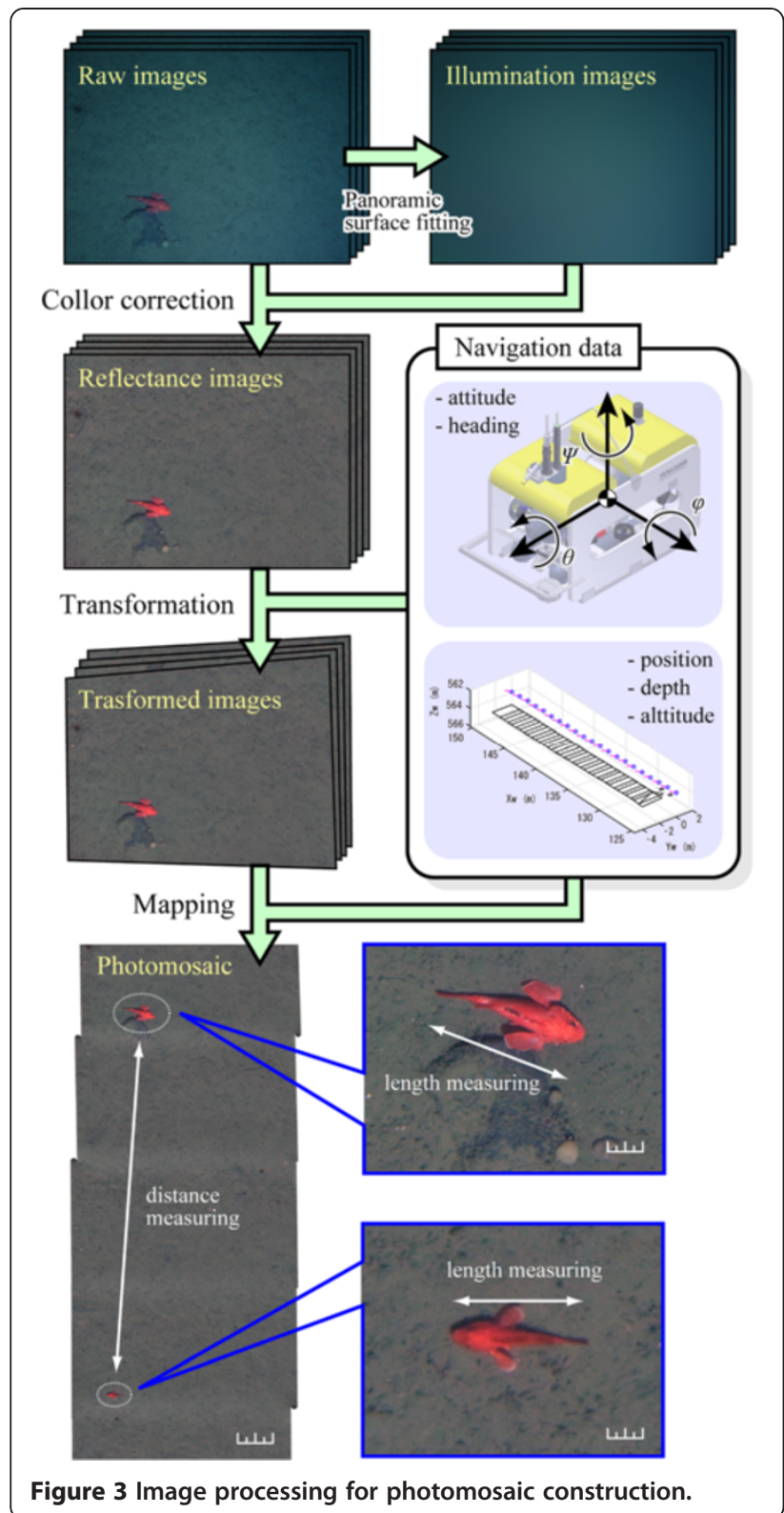

measure ground speed and altitude, and starts to control its altitude. Then, an INS is aligned by ground speed from a DVL again. The vehicle navigates at a constant velocity and altitude along target route after the alignment, and takes a picture of the seafloor using a camera and a strobe every ten seconds. If a forward camera for light-section method detects the obstacle, the vehicle goes up by horizontal thrusters to high altitude than height of the obstacle for avoidance. The AUV TunaSand releases a mounted weight and goes up by one's own positive buoyancy after reaching to final way point. And then, the vehicle reaches the depth close to surface and turns off all thrusters, observation devices. If monitored vehicle status such as battery voltage, inside

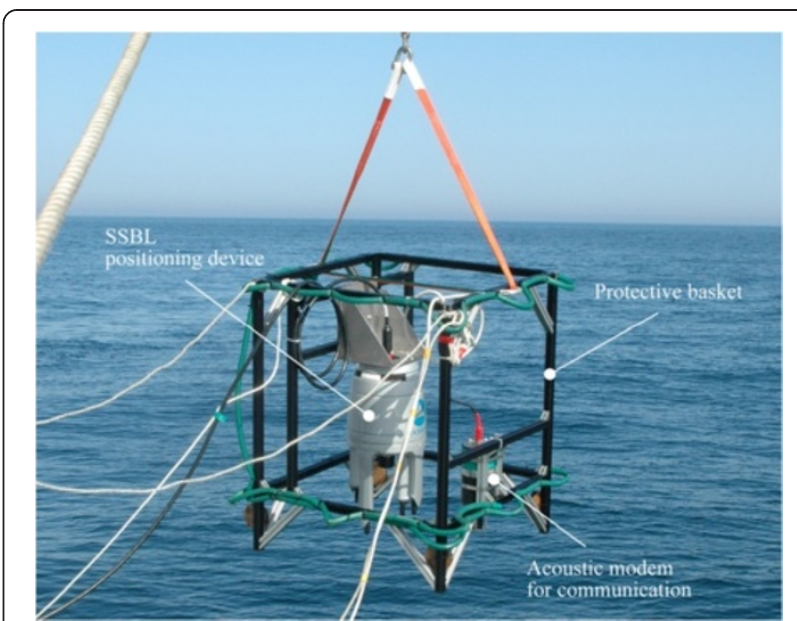

Figure 4 The basket for positioning and communication.

temperature and duration time is an abnormality during the survey, the survey is canceled. The vehicle surfaces positively every times even if it is out of control due to the accident. The reason is that two weights mounted on the vehicle are released automatically after the batteries runs down.

\section{Image processing method}

Taken photographs of the seafloor are corrected and transformed, to measure the biomass of kichiji rockfish and see ambient environment accuracy from the image. Figure 3 shows our imaging process method. The photograph pixel has the unevenness of the brightness $s$ due to distance between from light source. First, the color and the illumination in the photographs are corrected using the method proposed by Singh [10]. Let input image $\mathrm{F}$ be expressed reflection image $\mathrm{R}$ and illumination image I as

$$
F(x, y, \lambda)=I(x, y, \lambda) R(x, y, \lambda)
$$

where $\mathrm{x}$ and $\mathrm{y}$ denote the pixel coordinates and $\lambda$ denotes the color channel (red, green or blue). $I(x, y, \lambda)$ includes unevenness of the brightness in $F(x, y, \lambda)$. Thus, we are able to obtain uniform brightness image if $I(x, y, \lambda)$ is remove from $F(x, y, \lambda)$. The logarithm of illumination component formed by a single strobe in the water is known to be represented by fourth order polynomial of two variables as

$$
I_{L}(x, y) \approx p_{1} x^{4}+p_{2} x^{3} y+\cdots p_{14} y+p_{15}=\mathbf{S P}
$$

where $\boldsymbol{S}$ refer to surface fitting matrix for each pixel and $\boldsymbol{P}$ is the parameter vector. The least square method estimates $\boldsymbol{P}$ from a collar channel $F_{L}(x, y)$ represented by the logarithm of $F(x, y, \lambda)$. Clear image without luminance irregularity can be obtained by that $F_{L}(x, y)$ removed $I_{L}(x, y)$ 
Table 2 Outline of the survey

\begin{tabular}{|c|c|c|c|c|c|}
\hline & TS_073 & TS_074 & TS_076 & TS_077 & TS_079 \\
\hline Depth (m) & $143-144$ & $1,045-1,050$ & $652-757$ & $305-498$ & $561-566$ \\
\hline Location (lat.) & $N 144^{\circ} 40.5^{\prime}$ & N $144^{\circ} 39.0^{\prime}$ & N $144^{\circ} 54.0^{\prime}$ & N $144^{\circ} 51.0^{\prime}$ & N $144^{\circ} 37.2^{\prime}$ \\
\hline Location (long.) & E $144^{\circ} 11.5^{\prime}$ & E $144^{\circ} 20.0^{\prime}$ & E $144^{\circ} 26.4^{\prime}$ & E $144^{\circ} 24.0^{\prime}$ & E $144^{\circ} 17.0^{\prime}$ \\
\hline Cruising speed (m/s) & 0.12 & 0.12 & 0.12 & 0.12 & 0.12 \\
\hline Cruising height (m) & 2.1 & 2.5 & 2.5 & 2.5 & 2.5 \\
\hline Route type & Grid & Grid & Straight & Straight & Straight \\
\hline Duration (h) & 4.0 & 6.0 & 4.8 & 6.4 & 3.3 \\
\hline Observation area $\left(\mathrm{m}^{2}\right)$ & 340 & 2,600 & 3,400 & 5,500 & 440 \\
\hline Photography number & 158 & 1,593 & 1,310 & 2,077 & 159 \\
\hline Number of kichiji & 0 & 2 & 23 & 2 & 10 \\
\hline Density of kichiji (/ha) & 0 & 0 & 68 & 4 & 227 \\
\hline
\end{tabular}

is converted to linear scale. Note that $I_{L}(x, y)$ includes lowfrequency component of the seafloor and the benthic life in the photograph. However, the benthic life is easy to be seen from obtained color correction image because low its low-frequency component is lower than the other in illumination image.

Second processing in our method transforms the color correction image, considering navigation data and seafloor topography. The benthic life length cannot be measured from all photographs in the same scale, because seafloor topography changes camera-to-subject distance and water flow applies the vehicle attitude. The

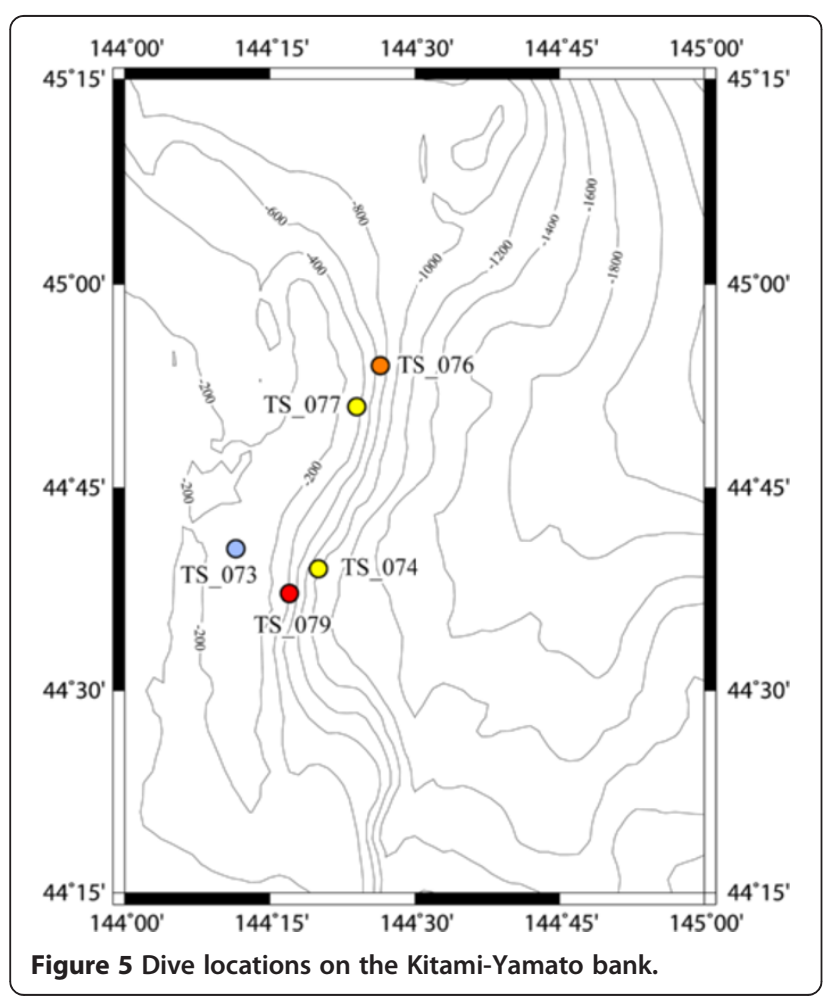

central projection of the camera distorts the photograph depending on the height and position of objective. Ortho-correction converts the images using navigation data and seafloor topography for precise measurement. Time-series altitude of the vehicle estimates the seafloor topography. Final processing in our method makes the photomosaic based on the vehicle trajectory.

\section{Results and discussion}

\section{Survey outline}

The biomass of kichiji rockfish was surveyed in KimitaYamato bunk supported by fisheries research vessel HOKKO-MARU on June 2013. The bunk which is $80 \mathrm{~km}$ height and the width of 4 to $7 \mathrm{~km}$ is located off northern Hokkaido in Japan. The basket mounted SSBL positioning device and acoustic modem is launched in the sea to monitor position and status of the AUV Tuna-Sand during the survey on the vessel. Figure 4 shows the picture of the basket for monitoring and Table 2 shows dive outline for the survey. Kichiji rockfish live at the depth of 150 to $1,200 \mathrm{~m}$ and are normally found in the seabed slope. This research surveyed in five points such as at the depth of 143 to $144 \mathrm{~m}$ on the topside, the depth of 305 to $498 \mathrm{~m}$ on the north, the depth of 561 to $566 \mathrm{~m}$ on the foot, the depth of 652 to $757 \mathrm{~m}$ on the north and the depth of 1,045 to $1050 \mathrm{~m}$ on the foot in the bunk. The vehicle navigated along the route of a reticular pattern for the detail survey in 73th and 74th dives, and the starlight line for wide area survey in 76th, 77th and 79th dives. Although target altitude in only 73th dive was $2.1 \mathrm{~m}$ (1.9 m swath width), target altitude in other dive was changed to $2.5 \mathrm{~m}$ (2.2 $\mathrm{m}$ swath width) because salty water in Kitami-Yamato bank was very clear.

\section{Survey results}

The AUV Tuna-Sand surveyed for 24 hours and took about 5,300 pictures of the seafloor, during five dives in 


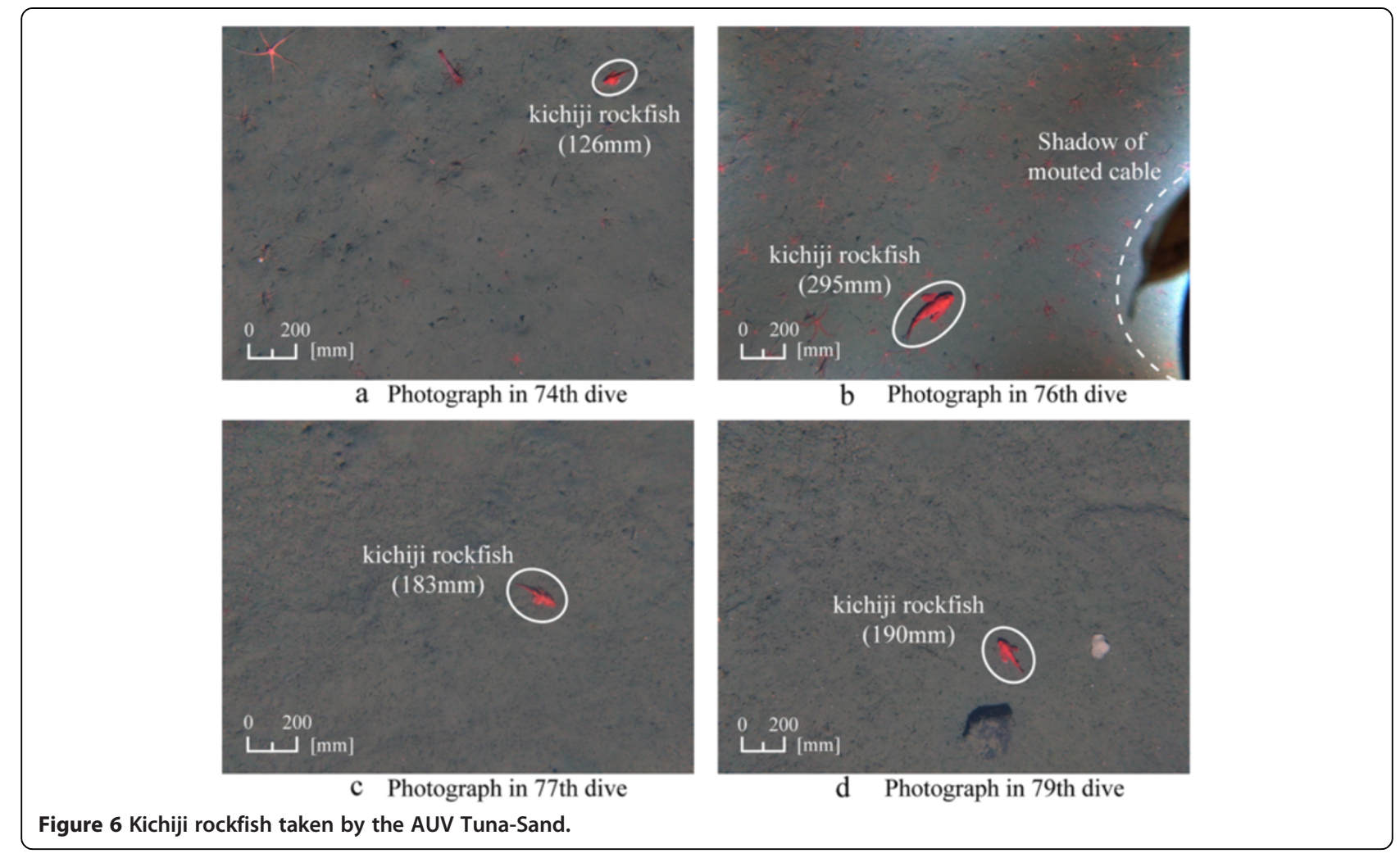

Kitami-Yamato bank. 37 kichiji rockfishes of about 90 to $340 \mathrm{~mm}$ long were in the photographs. All fishes stayed on seafloor and nobody avoided to somewhere. The result suggests our method using the vehicle is effective in resource investigation for kichiji rockfish. Figure 5 shows dive points in Kitami-Yamato bank and Figure 6 shows photographs taken on the survey. Photographs taken on 73th dive had no kichiji rockfish although a little of snow crabs and sea cucumbers. Two kichiji rockfishes and many brittle stars [11] which was the food for

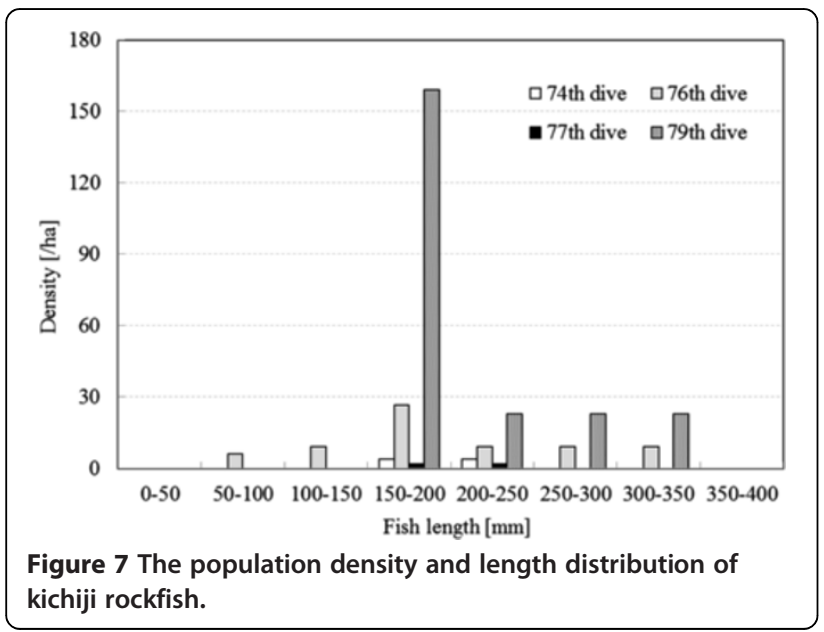

kichiji rockfish were found at the deepest in the survey in 74th dive (Figure 6(a)). The greatest number of kichiji rockfish and brittle star in the survey stayed on the seafloor and the density of kichiji rockfish was 68 fishes per a hectare in 76th dive (Figure 6(b)). 77th and 79th dive areas had a few brittle stars, and were 4 fishes per a hectare and 227 per a hectare respectively (Figure 6(c) and (d)). Above results suggest that kichiji rockfish likes to live in seabed slope and its biomass does not depend heavily on the number of brittle star.

Figure 7 shows the density of kichiji fish for each length. The fish of 150 to $200 \mathrm{~mm}$ long that was bout three years olds was most often found in all dives, although the number of the other long was not many. The reason is considered that many young fish less than $100 \mathrm{~mm}$ long swim at the altitude higher than observational altitude without staying on the seafloor. And the number of the old fish larger than $200 \mathrm{~mm}$ is small because they have many opportunities to be cached by fisher.

Figure 8 shows six mosaic images mad from pictures taken in 79th dive. The circle denotes kichiji rockfish and the square denotes other fish in Figure 8. The figure shows that all kichiji rockfish stay on the seafloor by oneself without swam, the shortest distance between kichiji rockfish is $4.0 \mathrm{~m}$ and the shortest between kichiji rockfish and other is $0.8 \mathrm{~m}$. 


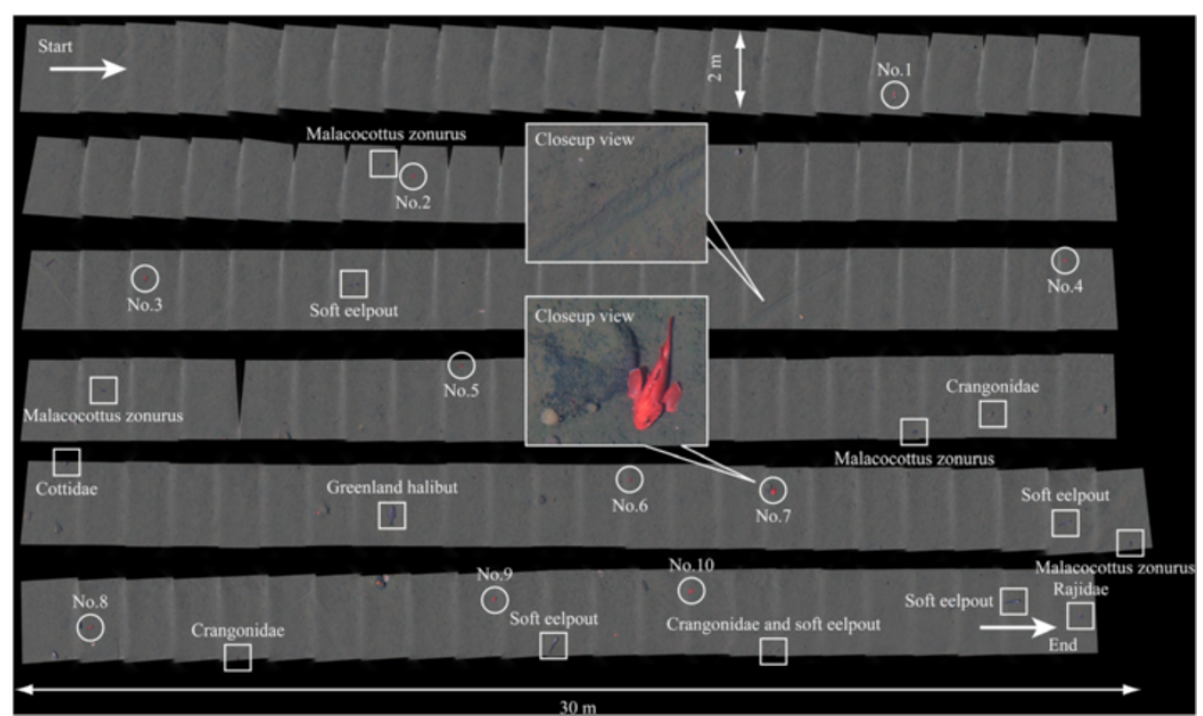

Figure 8 Six constructed photomosaic images comprising a linear photomosaic.

\section{Conclusion}

This paper proposed resource investigation method by the AUV Tuna-Sand and image processing method for clear photomosaic. The investigation method can survey without big support of the ship, because the vehicle can navigate automatically on rough terrain where is difficult to operate by human and take high-resolution picture of seafloor. Our image processing can measure accurately the fish length and the biomass, because it corrects the photograph color for removing the unevenness of the brightness and image distortion. The survey results using our method in Kitami-Yamato bank showed the density of kichiji rockfish for each length. A photomosaic having uniform brightness shows the fish distribution. These results contribute to keep sustainable use of kichiji rockfish. Our method applies to survey the biomass of other benthic animals such as snow club. We will develop method that can survey the biomass of several benthic animals at one time.

\section{Authors' contributions}

YN operated our vehicle for the survey, and made photomosaic. TU organized the survey, and enumerated the fishes in images. TH identified fish species. KN supported the survey. SI supported the survey. TN developed the vehicle. All authors read and approved the final manuscript.

\section{Acknowledgements}

The authors thank the staff of the fisheries research vessel HOKKO-MARU for their help and support. This work was supported by JST CREST "Establishment of core technology of the preservation and regeneration of marine biodiversity and ecosystems".

Received: 17 January 2014 Accepted: 9 May 2014

Published online: 23 July 2014

\section{References}

1. Masashi N, Shuichi K, Yasushi K, Takahiro K (2001) Estimates of population size of kichiji rockfish sebastolobus macrochir from Tag recoveries in southern Okhotsk Sea. Jpn Soc Scientific Fisheries 67(5):821-828

2. Tsutomu H, Narimatsu Y, Masaki I, Yuji U, Daiji K (2006) Annual changes in population size and recruitment per spawning biomass of bighand thornyhead Sebastolobus macrochir in the western North Pacific Ocean off northern Japan. Jpn Soc Scientific Fisheries 72(3):374-381

3. Toshihiro W, Taro H (2001) Estimation of the snow crab chionoecetes opilio population density using the deep-sea video monitoring system on a towed sledge. Jpn Soc Scientific Fisheries 67(4):640-646

4. Toshihiro W, Kazutoshi W, Daiji K (2003) Method of estimating the population density of kichiji rockfish Sebastolobus macrochir using a deep-sea video monitoring system on a towed sledge. Jpn Soc Scientific Fisheries 69(4):620-623

5. Michimasa E (1982) 2,000M Deep Submergence Research Vehicle "SHINKAI 2000" System. In: Proceedings of OCEANS, Washington. 20-22 September

6. Tomonori H, Takashi Y, Youji N (2003) Estimation of the fishing efficiency of kichiji rockfish, Sebastolobus macrochir, by comparison of the trawl survey and the submarine survey. JAMSTEC J Deep Sea Res 22:63-70

7. Takeshi N, Ura T, Takashi S (2008) Autonomous underwater vehicle "tuna-sand". J Japan Institution of Mar Eng 43(4):523-526

8. Sulin T, Tamaki U, Takeshi N, Blair T, Tao J (2009) Estimation of the hydrodynamic coefficients of the complex-shaped autonomous underwater vehicle TUNA-SAND. J Mar Sci Technol 14(3):373-386

9. Toshihiro M, Ayaka K, Tamaki U (2011) Volumetric mapping of tubeworm colonies in Kagoshima Bay through autonomous robotic surveys. Deep Sea research part I: oceanographic research papers. 58(7):757-767

10. Hanumant S, Chris R, Oscar P, Ali C (2007) Towards high-resolution imaging from underwater vehicles. International J Robotics Res 26(1):55-74

11. Toshiaki O, Tomonori H, Toyomi T (2005) Food habits of kichiji rockfish Sebastolobus macrochir in summer on the continental slope off the Pacific coast of Hokkaido, Japan. Jpn Soc Scientific Fisheries 71(4):584-593

doi:10.1186/s40648-014-0002-y

Cite this article as: Nishida et al.: Resource investigation for Kichiji rockfish by autonomous underwater vehicle in Kitami-Yamato bank off Northern Japan. ROBOMECH Journal 2014 1:2. 